\title{
Presumed superficial haemosiderosis presenting with subarachnoid haemorrhage
}

\author{
Michael S Lundin, ${ }^{\oplus 1,2}$ Samuel L Carter, ${ }^{2,3}$ Ali Saeed, $_{1}^{2,3}$ Rajit Pahwa $^{4}$
}

'Internal Medicine, Michigan State University, East Lansing, Michigan, USA

${ }^{2}$ Hospital Medicine, Sparrow Hospital, Lansing, Michigan, USA

${ }^{3}$ Neurology, Michigan State University, East Lansing, Michigan, USA

${ }^{4}$ Neurointensive Care, Sparrow Hospital, Lansing, Michigan, USA

\section{Correspondence to} Dr Michael S Lundin, lundinmi@msu.edu

Accepted 29 May 2019

\section{DESCRIPTION}

A 78-year-old man with a medical history of coronary artery disease with stents placed 8 years prior and coronary artery blood graft 6 years prior, on aspirin $325 \mathrm{mg}$ daily; congestive heart failure; diabetes mellitus; presented to the emergency department with a chief complaint of left arm weakness and numbness which resolved prior to arrival. A CT scan of his head showed right parietal subarachnoid haemorrhage. The patient was admitted to the neurointensive care unit. A CT angiogram showed no definite bleed. However, MRI redemonstrated acute right-sided frontal convexity surface subarachnoid haemorrhage, as well as generalised siderotic changes (figure 1). Gadolinium imaging raised the possibility of a subtle pial dural arteriovenous graft. Subsequent catheter angiographic brain imaging was negative for any vascular malformation or aneurysm.

The patient relates that he has had four previous such episodes with stereotypical features starting 1 year ago: his left hand feels big, abnormal feeling and paresthesia radiate up his left upper extremity, and then his legs buckle. This episode was similar to all of those previous episodes except that he had dysarthria too.

The patient was diagnosed with superficial haemosiderosis. Aspirin $325 \mathrm{mg}$ was permanently discontinued (for the time being) with plans to possibly resume $81 \mathrm{mg}$ in the future. Levetiracetam $750 \mathrm{mg}$ two times per day, which was started at the time of admission, was continued.

Superficial haemosiderosis (also called cortical superficial siderosis) is a pattern of deposition of blood-breakdown products that occur in the sulci of the cerebral hemispheres. Superficial haemosiderosis' classical clinical presentation is irreversible,

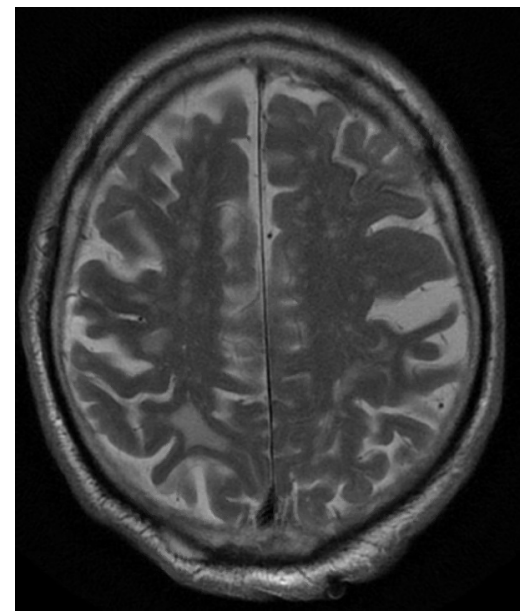

Figure 1 T2 imaging showing superficial siderosis.

\section{Learning points}

- Cerebral amyloid angiopathy is a risk factor for bleeding in the cranium. It can present acutely as intracranial haemorrhage. Chronically, however, small bleeds can deposit such as to form the superficial haemosiderosis pattern on imaging.

- Superficial haemosiderosis requires a biopsy to diagnose with certainty, but typically can be presumed from characteristic neuroimaging findings.

- It is important to identify brain abnormalities such as cerebral amyloid angiopathy or superficial haemosiderosis in medical practice for two major reasons: (1) they serve as a risk factor for bleeding and a reason to avoid anticoagulation or antiplatelet therapy when its benefit is questionable (eg, aspirin for primary cardiovascular prevention) and (2) they are structural lesions on neuroimaging which help justify the use of antiepileptic therapy in patients presenting with an epileptic seizure.

slowly-progressive ataxia with dysarthria and sensorineural hearing impairment. ${ }^{12}$ However, superficial haemosiderosis has been found to be a common and characteristic feature of cerebral amyloid angiopathy, ${ }^{3}$ which increases the risk of intracranial bleeding. This case is unique because the superficial haemosiderosis was detected in an acute manner after a subarachnoid haemorrhage.

Contributors MSL was the internal medicine resident who saw the patient and wrote the manuscript. SLC was the neurology resident on the stroke team who saw this patient and thought of the idea to write up the manuscript, as well as reviewed and edited it significantly. AS was the stroke attending who saw this patient and reviewed the manuscript. RP was the neurointensivist attending who saw this patient and reviewed the manuscript.

Funding The authors have not declared a specific grant for this research from any funding agency in the public, commercial or not-for-profit sectors.

Competing interests None declared.

Patient consent for publication Obtained.

Provenance and peer review Not commissioned; externally peer reviewed.

\section{REFERENCES}

1 Kumar N. Neuroimaging in superficial siderosis: an in-depth look. AJNR Am J Neuroradiol 2010;31:5-14.

2 Yamawaki T, Sakurai K. [Diagnosis and treatment of superficial siderosis]. Brain Nerve 2013;65:843-55.

3 Charidimou A, Jager RH, Fox Z, et al. Prevalence and mechanisms of cortical superficial siderosis in cerebral amyloid angiopathy. Neurology 2013;81:626-32. 
Images in...

Copyright 2019 BMJ Publishing Group. All rights reserved. For permission to reuse any of this content visit https://www.bmj.com/company/products-services/rights-and-licensing/permissions/

BMJ Case Report Fellows may re-use this article for personal use and teaching without any further permission.

Become a Fellow of BMJ Case Reports today and you can:

- Submit as many cases as you like

- Enjoy fast sympathetic peer review and rapid publication of accepted articles

Access all the published articles

Re-use any of the published material for personal use and teaching without further permission

Customer Service

If you have any further queries about your subscription, please contact our customer services team on +44 (0) 2071111105 or via email at support@bmj.com.

Visit casereports.bmj.com for more articles like this and to become a Fellow 